DOI: $10.20472 /$ IAC.2018.040.031

\title{
BOYOUNG KIM
}

The Catholic University of Korea, Korea, Republic of

SANG MIN LEE

Korea University, Korea, Republic of

\section{DEVELOPMENT AND PSYCHOMETRIC EVALUATION OF THE CAREER FLEXIBILITY INVENTORY}

\begin{abstract}
:
The purposes of this study were to develop and validate a new scale measuring career flexibility called the Career Flexibility Inventory. The scale was aimed at addressing the shortcomings of previously developed measurements, based on the reviews of career development theories and literature. Participants were university students residing in a metropolitan city in South Korea. The study included item content development, exploratory factor analysis, and confirmatory factor analysis and Pearson's correlation analysis was conducted with career-related measurements to verify the concurrent validity of the newly developed scale. The Career Flexibility Inventory consists of three dimensions: wavering, active adaptation, and flexible thinking. Wavering is passive career flexibility, active adaptation is proactive career flexibility, and flexible thinking is reactive career flexibility. Several limitations and implications of the current study were discussed for future studies.
\end{abstract}

\section{Keywords:}

career flexibility, career flexibility inventory, university students, career counseling, planned happenstance theory 